\title{
Methodology for managing financial risks of Kazakhstan enterprises
}

\author{
Baglan Alieva1,, ${ }^{1,}$ Abdizhapar Saparbayev ${ }^{2}$, Gaukhar Zhanibekova ${ }^{3}$, Myras Noiyanov $^{1}$, \\ Valeriy $\mathrm{Kim}^{4}$ \\ ${ }^{1}$ Al-Farabi Kazakh National University, al-Farabi Ave. 71, 050040 Almaty, Kazakhstan \\ ${ }^{2}$ Kainar Academy, Satpayev St., 7a, 050013 Almaty, Kazakhstan \\ ${ }^{3}$ Kazakh Ablai Khan University of International Relations and World Languages, Muratbayeva St., 200, \\ 050022 Almaty, Kazakhstan \\ ${ }^{4}$ University of International Business, 8A, Abay Ave., 050000 Almaty, Kazakhstan
}

\begin{abstract}
The article tells about the main types of financial risks on the example of Kazakhstan enterprises and JSC "KAZMUNAIGAS"RD. One of the main types of risks inherent in the Kazakh financial market at the present time was identified, the necessity of using coefficients for recognizing the degree of financial risks was proved on the example of a comparative study based on the VaR method, at the same time, the reasonableness of using futures and option contracts for insuring financial risks of organizations was proved.
\end{abstract}

\section{Intrduction}

In the current environment, when global relations determine the development of the national economy, the role of the financial market is increasing every day. Small and medium-sized businesses, as well as other private enterprises operating in Kazakhstan, are associated with the unstable positive impact of economic processes in the country, which accompanies processes such as regulation, control and supervision of the financial market, the legal framework of the financial market, and dependence on changes in the situation on the world market [1].

This issue presents the possibility of losing the company's stable financial position in the course of its operations. In this regard, the analysis of financial risks arising in the company's activities and authentication of management methods and techniques becomes significant. The research is based on methodological and theoretical developments of financial risk management and assessment systems.

As an independent scientific direction in financial risk assessments, financial econometrics should be singled out.its models and methods allow us to note the most important indicator of financial risk - volatility. Their development is devoted to the scientific works of Ayvazyan C., Eliseeva I., Mkhitaryan V., Bacheliev L., Green M., Campbell J., Lo V., Makkipley A., Taylor C., as well as Kazakh scientists Baymuratov U.,

\footnotetext{
* Corresponding author: rdd2011@mail.ru
} 
Chelekbay A. D., Abdrakhmanova G. T., Iskakova U. M., Spanova M. U., Zhanbolatova, A., Ziyadin, S., Zhumanov, K., Jumabekova, A. [2]

Each social life area has different approaches to define this notion and its boundaries. In spite of some expected favorable financial effect, the risk is inextricably bound up with probable material loss which can be caused by an unfavorable decision or circumstances, such as changes in market conditions or force majeure [3].

A wide range of issues related to the risks of companies, reflected in the works of Pukala, R., Sira, E., Vavrek, R. [4].

Despite the fact that a serious theoretical base in this area has been created in the country and in the world, this does not protect financial market entities from financial losses and big risks. Thus, one of the scientific problems is the organization of methods for assessing and managing financial risks and its improvement.

\section{Results and Discussion}

According to most companies, one of the main tasks is to have a unified risk management system. Many companies are implementing this system. Thus, according to independent experts, $66 \%$ of companies in Kazakhstan have introduced the position of risk Manager, and $21 \%$ are only going to apply this system. $30 \%$ and $35 \%$ of companies, respectively, have established a Commission and a Committee of Directors for risk management in their companies (Figure 1).

introduced \begin{tabular}{l|l|l|l|}
\hline & & & \\
\hline
\end{tabular}
it is planned to implement it in the near future
it is not planned to be implemented in the near
future

Fig. 1. Development of risk management in Kazakhstan companies [5].

In $47 \%$ of companies, the risk Manager is responsible for organization and support of risk management. In $18 \%$ of companies, the head of internal audit is responsible for monitoring the risk management process, While only $12 \%$ of organizations have the General Director responsible for the process of risk management. At the same time, $24 \%$ of risk managers are formally responsible to the General Directors, and functionally subordinate to the audit Committee (Figure 2).

In Asia, Australia, Western Europe and North America, top management of companies is an active participant in the field of risk management, and the CEO organizes this process. Such a clear difference in the approach to risk management in Kazakh companies can be explained to some extent by the difference in the culture of understanding risk management among the top management of companies. Concurrently, it should be considered that in Western Europe, the function of a company's risk Manager has a higher position in the 
management system than in Kazakhstan. In most countries in Asia, Australia and Western Europe, managers are part of senior management. In our country, internal auditors conduct risk management, which periodically report to the director of the company [6].

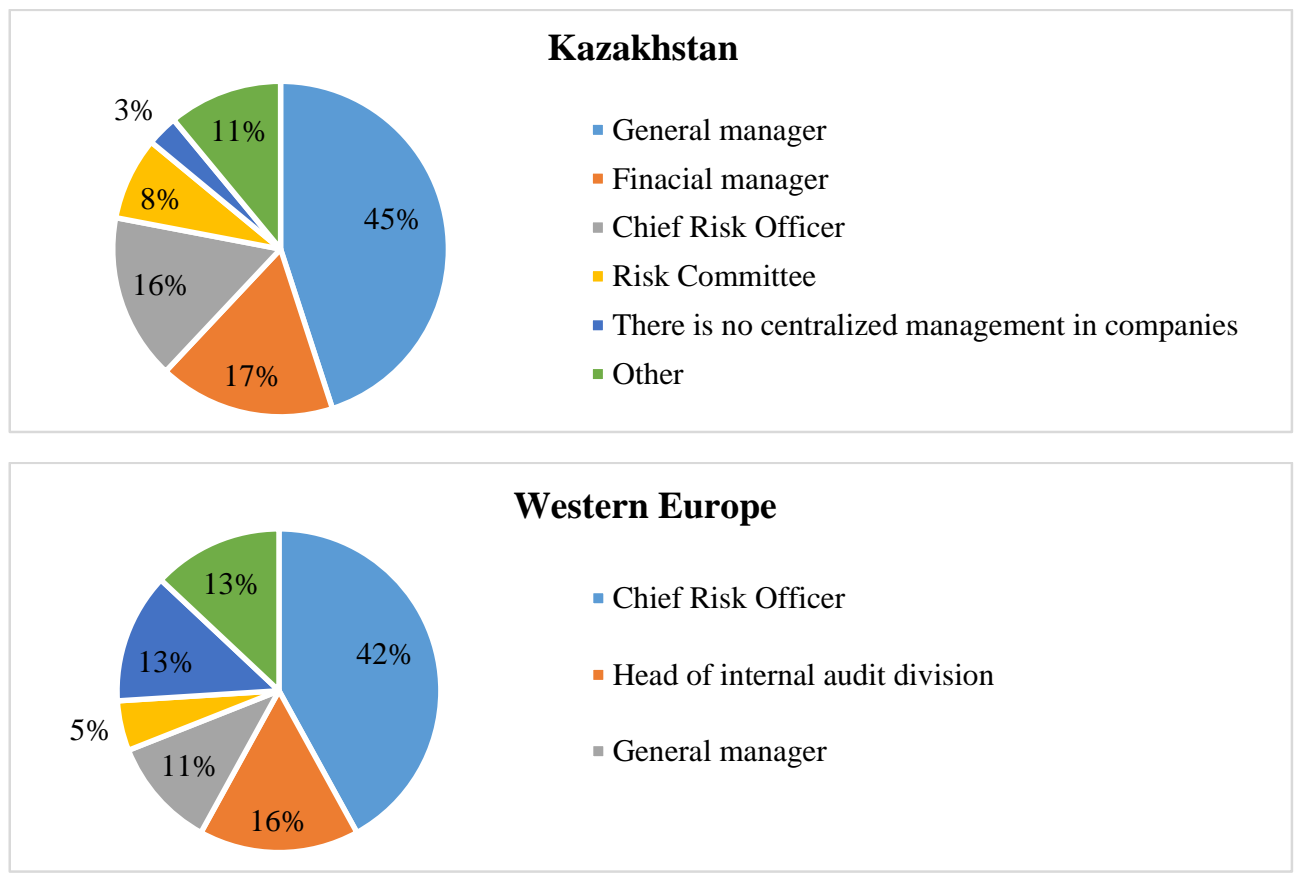

Fig. 2. Responsibilities for organizing and supporting the risk management process [5].

In the process of determining the highest risks for the company, the risk associated with personnel, according to $43 \%$ of Kazakhstani companies, is the most serious. According to $37 \%$ of companies, financial and credit risks rank 3rd in terms of threats. Companies in Western Europe believe that financial, credit and currency risks pose the greatest threat in today's unstable environment. This proves that CEOs are not sufficiently aware of the high risks to their companies. This is due to ignorance of risk assessment methods and techniques and incompetence of the staff.

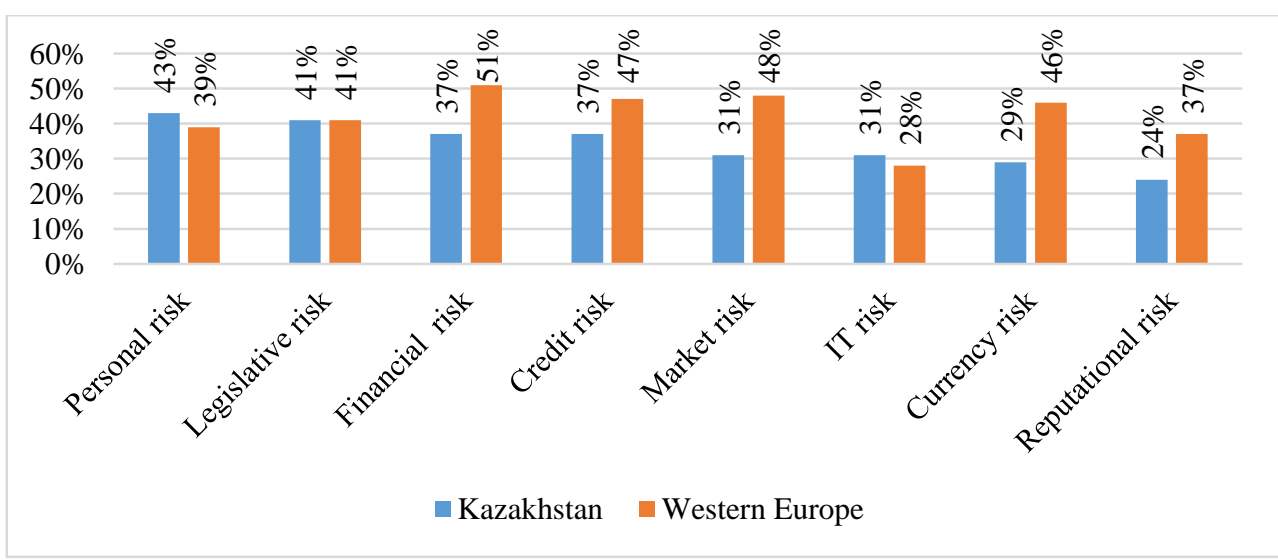

Fig. 3. Risks that present a very high and high degree of threat to companies' activities [6]. 
Although many companies claim an active risk management process, most of them do not know the limit of risk that their company can withstand in the event of unforeseen circumstances.

In the process of risk management, companies face certain difficulties during the formation of an effective risk management system. The main obstacles to risk management, $57 \%$ of Kazakhstani companies determine the lack of interaction between the company's functional divisions in terms of risk management, as well as the lack of corporate ethics for risk management. However, $43 \%$ of Western companies report poor quality of information received, while the remaining $36 \%$ of companies highlight the inability to obtain an accurate assessment of the company's risks. In Kazakhstan, $45 \%$ of companies put the poor quality of information received in the 3 rd place, $31 \%$ of companies put the inability to obtain an accurate risk assessment in the 3 rd place.

Most organizations consider the low efficiency of the developed risk assessment and management methods to be another barrier to the development of the risk management system. This may be because risk management systems in companies are not sufficiently clear and integrated. When implementing cost-cutting programs, many companies do not have the costs of outsourcing and implementing various software for assessing and managing financial risks, preferring to cope solely on their own. $12 \%$ of companies noted the lack of financial resources as another obstacle to improving the effectiveness of the process of risk management. Concurrently, a lack of understanding of the risk management process and almost complete lack of experience in the field of risk management lead to the fact that many enterprises in the economy's manufacturing industry mainly refer to the experience and opinion of experts when identifying and assessing risks. Quantitative risk assessment methods are not widely used. This is because of the lack of sufficient statistical information on cases of implementation of certain data that are necessary for quantitative risk assessment. In addition, insufficient training of company personnel in the field of risk management, as noted earlier, also significantly hinders the introduction of quantitative methods in companies [7].

Organizational and economic characteristics of KAZMUNAIGAS Exploration and Production. KazMunaiGas Exploration Production JSC (hereinafter referred to as KMG EP) is one of the leaders in oil production in Kazakhstan. The company is a producer of oil, natural and associated gas from its own hydrocarbon reserves located in fields in the Western and southern regions of Kazakhstan.

The company was formed in March 2004 by the merger of "Uzenmunaigas" (UMG) and "Embamunaigas" (EMG). After the successful initial placement of capital on the London and Kazakhstan stock exchanges at the end of 2006, because of the well-thought-out implementation of the acquisition policy, the investment program in fixed assets and effective measures to optimize costs, KMG EP has significantly strengthened its position in both the domestic and international markets. During the IPO in September 2006, the Company raised more than $\$ 2$ billion. KMG EP is a subsidiary of the national oil and gas company Of the Republic of Kazakhstan - KAZMUNAIGAS national Company (NC KMG), which owns $60.5 \%$ of KMG EP's common shares as of December 31, 2012.

KazMunaiGas Exploration Production JSC also actively conducts exploration to maintain and develop reserves and develops deposits. He has accounted for 41 deposits in Western Kazakhstan. The total area of the deposits is $837.4 \mathrm{~km} 2$. The production units of the company have been operating for over 90 years. The main production assets of the enterprise are its two production branches: UMG and EMG, whose total production level was 177,000 barrels of oil per day in 2010. The largest deposit in the portfolio of the enterprise is Uzen deposits. The share of Uzenskoye field is about $73 \%$ of all reserves $68 \%$ of total production. One of the main tasks of KMG EP is to ensure the growth of hydrocarbon reserves. This growth is possible due to the acquisition of new assets, exploration and optimization of production at 
the main fields [8]. According to experts, the total oil reserves in the "proven plus probable" (2P) category of AO KazMunaiGas Exploration Production as of the end of 2011 amounted to 225.816 million tons (1.661 billion barrels), excluding KMG EP's shares in Kazgermunai (KGM), CCEL (CCEL) and Petrokazakhstanink (PKI) in comparison with 232.082 million tons (1.707 billion barrels) at the end of 2010. In 2013, the company plans to increase oil production by $2 \%$ to 13.5 million tons [9].

The company is sensitive to market risks: volatility in oil prices, exchange rates, and floating interest rates on loans. The decline in oil prices will significantly affect the company's financial performance. KMG performs mathematical modeling of price risk and compares the results with the planned indicators. The company is able to quickly optimize costs and capital investments when oil prices fall, and does not exclude the possibility of purchasing financial instruments to protect against a significant drop in oil prices [18].

Changes in interest rates may also have a negative impact on the cost of placing temporarily available funds (VAS) and, consequently, on the company's financial results. To minimize this risk, the Company diversifies the placement into financial instruments in the specified parameters of the Treasury investment portfolio and regularly monitors the placement of the VSD for the companies of KMG. As a result of risk management, the Company provides the required return on the VSD. In addition, in order to manage financial risks, the Company has introduced a practice of limiting them by setting limits on balance sheet and off-balance sheet liabilities for counterparty banks [18].

The market category includes risks of adverse effects of changes in oil prices, exchange rates, and interest rates. The company provides wholesale oil supplies, both in the domestic and foreign markets. The main possible deterioration for both domestic and foreign markets is the declination in prices of oil, which implies significant variability due to a number of factors: the balance of supply and demand, the influence and policy of the main oil-producing countries, and the political situation in the main regions of energy production. The decline in global oil prices will significantly affect the company's financial performance. The company does not resort to hedging the risks of lower oil prices now, but in each specific situation uses internal cost management tools to reduce the negative impact of this risk.

The industrial organization operates in Kazakhstan and the main currency of its accounts is tenge. The costs associated with payment of wages, electricity costs, and logistics services are sensitive to tenge inflation.

The Company's operations are subject to the risk of changes in interest rates, which may negatively affect the cost of placing temporarily available funds and, consequently, the company's financial results.

The main source of borrowing is the international credit market. The main part of the company's debt portfolio is loans denominated in US dollars. The interest rate for servicing some of these loans is based on the rates for LIBOR and EURIBOR interbank loans. An increase in these interest rates may increase the cost of servicing the Company's debt. The increase in the cost of loans for the Company may have a negative impact on its solvency and liquidity indicators [16].

Due to negative publications in the media, the Company is exposed to reputational risk that affects its business reputation and relationships with investors, partners and other interested parties. The company carries out a set of measures to manage this risk, including daily monitoring of publications in the media about the Company's activities, organizing briefings, press conferences, and management speeches in order to ensure sufficient coverage of various aspects of the Company's activities, as well as timely response to negative publications in the media [18]. In General, the planned work on managing the Company's key risks in 2016 was completed in full. The company has taken appropriate actions to manage main risks in order to reduce the likelihood of their implementation and minimize / prevent possible financial losses [18]. As part of KMG's transformation processes and further 
improvement of the CSR, work will continue in 2017 to develop and implement an internal control system (process-level risk management) in KMG group companies, as well as to develop and implement a business continuity management system (risk management leading to business interruption) [18].

A significant portion of the Company's revenue is denominated in US dollars or pegged to the us dollar. Some of the Company's expenses are denominated in a foreign currency, or otherwise depend significantly on fluctuations in foreign exchange rates (mainly the US dollar, to a lesser extent the Euro and the ruble) relative to the tenge. Currently, most of the company's current expenses are paid at prices set in tenge.An appreciation of the dollar will make oil exports more profitable.

If there is a negative impact of changes in interest rates and exchange rates, the Company will take the following actions to reduce the negative consequences:

1) expanding the range of partner banks, primarily at the expense of the institutions least affected by the current global financial crisis;

2) more extensive use of trade Finance instruments (letters of credit, guarantees) that reduce the company's dependence on basic interest rates. The most susceptible to change because of the impact of these financial risks are such indicators of the Company's financial statements as:

- net profit;

- revenue;

- cost price

- receivables.

Credit risks are exposed to transactions related to the movement of material and cash flows with counterparties, starting with financial institutions that serve the Company's financial flows, and ending with buyers of final products and contractors that provide a variety of services to the Company. An effective centralized cash management system implemented by the Company's Treasury allows minimizing credit risks (Table 1) [9].

Table 1. Financial risks, probability of their occurrence and nature of changes in the reporting.

\begin{tabular}{|l|c|l|}
\hline \multicolumn{1}{|c|}{ Risks } & $\begin{array}{c}\text { Probability of } \\
\text { occurrence }\end{array}$ & \multicolumn{1}{|c|}{ Nature of the change } \\
\hline $\begin{array}{l}\text { Falling interest rates on Bank } \\
\text { deposits }\end{array}$ & Medium & $\begin{array}{l}\text { Decrease in profit due to a drop in revenue } \\
\text { from placing temporarily available funds }\end{array}$ \\
\hline $\begin{array}{l}\text { Currency risk } \\
\text { (risk of devaluation of the tenge } \\
\text { against the Euro and the us dollar) }\end{array}$ & Medium & $\begin{array}{l}\text { Increase in the cost of purchased } \\
\text { equipment - increase in depreciation } \\
\text { charges }\end{array}$ \\
\hline Inflation risk & Medium & $\begin{array}{l}\text { Increase in accounts receivable, increase } \\
\text { in the cost of services produced }\end{array}$ \\
\hline Credit risk & Medium & $\begin{array}{l}\text { Distressed accounts receivable, reduced } \\
\text { profit }\end{array}$ \\
\hline Note: compiled by the author based on data from the official website of KMG EP \\
\hline
\end{tabular}

Several factors complicate the planning of tax costs of the enterprise. These factors include: the low applicability of recently adopted laws, the risk of additional taxes, fines and penalties due to incorrect disclosure of regulations. Managers and management of the enterprise determines measures to reduce the level of this risk by using the Tax Code and its amendments.

Foreign economic activity may cause additional risk factors, such as changes in customs control rules, ITP volatility and the lack of a transparent formula for calculating ITP. The company regularly monitors changes in the current legislation of the Republic of Kazakhstan and takes them into account in its activities. This minimizes the risks associated with these 
changes.

The main operational risks of the company include the risks associated with exploration and mining. The following is a list of the most important operational risks, to which the Company allocates large resources to minimize, and pays considerable attention both in its daily activities and in the planning and performance evaluation process.

The main factors that affect investment activities of the company are:

- limited availability of new onshore assets available for acquisition in Kazakhstan;

- increased competition from major international oil and gas companies for access to oil and gas assets;

- lack of own highly effective service expertise that enables KMG EP to participate in offshore projects in Kazakhstan.

In addition, KMG EP is the biggest oil and gas mining company that is controlled by the government. In this regard, the state depicted by Samruk Kazyna and KMG NC can influence KMG EP in the interests of the state as a whole, which may contradict the interests of KMG EP shareholders. All these factors, can lead to underestimation/re-evaluation of the attractiveness of projects, inefficient investment decisions and, as a result, to a reduction in the level of reserves and a drop in the Company's value [9].

Reduced organizational capacity is also a key factor that affects the company, as highly qualified personnel is one of the competitive advantages of the company and creates the basis for achieving the goals and objectives of the company. The problem of recruiting staff every year is facing the company. This is primarily due to the inability to recruit staff, due to the lack of the necessary category of specialists in the labor market in certain regions. When managing this type of risk, the company uses different methods to minimize it. The company is trying to increase the loyalty, motivation and professional level of employees. Much attention is also paid to developing leadership management skills and the formation of a talent pool.

Allocation of resources is not in the best interests of the Company, damage to the Company in order to obtain personal benefit; any evidence of corruption is completely unacceptable in the Company's activities, regardless of the amount of financial damage. The company uses various measures to prevent illegal actions and damage the reputation of the company. The company is subject to the Anti-Corruption Law of the Republic of Kazakhstan and the UK Bribery Act of 2010, which entered into force in 2011, and is pursuing an internal policy in accordance with these laws [9].

Table 2. Financial and economic indicators of KAZMUNAIGAS RD JSC».

\begin{tabular}{|l|l|l|l|l|}
\hline & 2015 & 2016 & 2017 & 2018 \\
\hline ROS & $0,95 \%$ & $0,17 \%$ & $0,20 \%$ & $0,02 \%$ \\
\hline ROA & $0,25 \%$ & $0,06 \%$ & $0,08 \%$ & $0,02 \%$ \\
\hline ROE & $0,28 \%$ & $0,06 \%$ & $0,09 \%$ & $0,03 \%$ \\
\hline Absolute liquidity ratio & 0,65 & 0,58 & 1,22 & 0,84 \\
\hline Current liquidity ratio & 4,50 & 3,64 & 4,02 & 5,06 \\
\hline Share of borrowed capital in Assets & $22,58 \%$ & $18,84 \%$ & $15,73 \%$ & $14,47 \%$ \\
\hline Note: compiled by the author based on the annal report of KMG EP for 2016 \\
\hline
\end{tabular}

From the data in Table 2, there is a decrease in the turnover ratio for some indicators, in particular: the turnover ratio of assets in 2016 decreased by 0.23 (from 0.65 to 0.42 ), for accounts receivable-by 2.81 (from 13.76 to 10.96). The trend continued in 2017, unless asset turnover increased slightly by 0.03 . As for the other coefficients, although there was a slight decline in the inventory turnover coefficient in 2016 (from 22.87 to 22.09), this coefficient increased by 2.54 in 2017. The turnover ratio of accounts payable increased by 1.1 and 0.44 respectively in 2015-2016. This is a negative point for the company, because a decrease in the value of turnover ratios is a reflection of a decrease in the rate of turnover of capital and 
the production process. The economic effect of this factor is expressed in the relative withdrawal of funds from circulation, as well as in an increase in the amount of revenue and the amount of profit.

In General, evaluating the financial and economic indicators of the company, it is concluded: KAZMUNAIGAS RD JSC needs to reduce operating and non-operating expenses. The company should pay attention to the value of the financial stability ratio. The growth and excess of this ratio is a fairly positive factor for the company, because it indicates a stable position of the enterprise.

We will conduct financial risk assessments of KAZMUNAIGAS RD JSC using the var quantitative assessment method. The Value at Risk method has been widely used among financial organizations since the mid-90s of the XX century. The group of Thirty (G30) first recommended this technique in 1993 in the work "Derivatives: Practice and Principles". J. P. Morgan, one of the largest investment companies in Risk Metrics, further contributed to the VaR valuation study. As a result, in 1995, the Basel Committee on banking supervision recommended the VaR methodology as the main approach to risk assessment.

$\mathrm{VaR}$ is an estimate expressed in the base currency of the amount that will not exceed the expected losses over a given period of time with a given probability. VaR is a universal method for calculating various types of risk: market;

- price risk - the risk of changes in the value of the price of a financial asset in the

- $\quad$ currency risk - the risk of losses due to adverse changes in the exchange rates of foreign currencies and (or) precious metals (foreign exchange metals);

- credit risk - financial risk of a debtor's default on its obligations to a supplier of goods or a service provider, that is, the risk of a debtor defaulting;

liquidity risks are the risks of losses caused by the mismatch of the maturities of liabilities for assets and liabilities [10].

Traditionally, VaR calculation methods are divided into:

(1) historical;

(2) parametric (variational-covariance models);

(3) simulation method (Monte Carlo method).

Method of historical modeling. Var estimation using the historical modeling method in the classical version is performed as follows. At the first stage, the initial set of indicators is determined - the values of the value of the portfolio in question for all market conditions recorded in the historical period (in our case, the daily change in exchange rates).

At the second stage, the resulting time series is translated into a series of relative changes using the formula [10]:

$$
\Delta_{i}=\frac{y_{i}-y_{i-1}}{y_{i-1}}
$$

At the third stage, the received changes are ordered and cleared by the part of the worst values that exceeds the accepted confidence level. The worst value left corresponds to the maximum probable loss value within the accepted confidence level, i.e. VaR.

At the final fourth stage, the resulting relative var score is converted to an absolute monetary equivalent [12].

To determine the price risk, namely oil prices using the Value at Risk (VaR) method, the annual historical indicator of the price of Brent crude oil was used.

$\mathrm{VaR}$ is characterized by three parameters:

1. The Time horizon that depends on the situation in question. According to the Basel documents-10 days, according to the Risk Metrics method-1 day. The calculation with a time 
horizon of 1 day is more common. 10 days is used to calculate the amount of capital covering possible losses.

2. Confidence level-the level of acceptable risk. According to the Basel documents, the value $99 \%$ is used, in the RiskMetrics system $-95 \%$.

3. The base currency in which the indicator is measured.

The calculation begins with calculating the mathematical expectation of daily price changes from January 01, 2012 to the present day. The mathematical expectation is the average value of a random variable, and the probability distribution of a random variable is considered in probability theory. In this case, the mathematical expectation is $-0.04 \%$.

The next step is to determine the standard deviation. The standard deviation is an indicator of the dispersion of values of a random variable relative to its mathematical expectation. In this case, the standard deviation is $1.35 \%$.

Next, we find the Quintile for our model. A quintile in mathematical statistics is a value that a given random variable does not exceed with a fixed probability. To determine VaR, we will apply a $99 \%$ probability according to the Basel documents. In this case, the quintile is $3.2 \%$.

So, first, let us calculate the price for the day ahead according to the Risk Metrics method. The price of Brent crude oil on April 22, 2013 is \$99.07. Multiplying this price by a quintile and the resulting values $X(1)=95.92$, this means that during the next day, the oil price will not fall below the value of 95.92 tenge with a $99 \%$ probability.

According to the Basel documents, the time horizon that depends on the situation in question is 10 days. Then multiplying this price by the quintile and the square root of ten, we get the values $X(10)=89.11$, which means that over the next ten days, the oil price will not fall below the value of 89.11 tenge with a $99 \%$ probability.

Therefore, based on the above, the company can forecast future cash flows and assess future price risks for further hedging.

Now it is necessary to conduct stress testing of the financial risks of KAZMUNAIGAS RD JSC. Today, in the world of global structural and technological changes, where an incident in one part of the planet can cause amplitude price variations around the world, there are situations that cannot be predicted in any way. Recently, companies have chosen to use stress testing in risk management. Stress testing is a method of analyzing the risks of financial organizations, individual sectors, markets or the financial system as a whole and assessing their resistance to the realization of exceptional but probable shocks.

When stress testing, we especially look at how financial instruments behave in the event of a certain stressful situation, for example:

- what happens if stock markets crash by more than X\% this year?

- what happens if GDP falls by Z\% during a given year?

- what happens if interest rates rise by at least Y\%?

- what should I do if half of the instruments in the portfolio are terminated in five years?

- what happens if the price of oil rises by $200 \%$ ?

The emphasis on the adequacy (taking into account risk) of the definition of capital was reinforced by changes in banking legislation (Basel II). Stress testing of models in most cases allows taking into account not only individual risk factors, but also combinations of various events. For example, you can analyze the influence of known historical events on the liquidity of this enterprise. Stress testing models reflect portfolio stability in the implementation of forecasts, and allow you to see possible weaknesses in the organization. Even if the company cannot predict extreme events, knowledge of the impact of their consequences on the organization's performance improves an understanding of the situation. Stress testing allows you to determine the degree of influence of a particular event on the company by using a special algorithm.

Below is a list of script types: 
1. Extraordinary events: a historical event that has already occurred is often used as an event.

2. Risk factor shock: the shock of any factor in the selected risk model for a user-defined amount.

3. External or unmanageable risk factor: the risk factor is any macroeconomic index or established indices.

This section is devoted to determining the stability of the KMG EP system to various structural macro and microeconomic risks. The dependent variable in this model is the company's annual revenue. The first step is to build a simple pair regression model. [13]:

Pair regression is a regression between two variables $-\mathrm{y}$ and $\mathrm{x}$, i.e. a model of the form

$$
\mathrm{Y}(\mathrm{x})=\mathrm{f}^{\wedge}(\mathrm{x})
$$

where, $y$ is the dependent variable (the result attribute);

$\mathrm{x}$ is an independent, or explanatory, variable (attribute-factor). The " $\wedge$ " sign means that there is no strict functional relationship between the variables $\mathrm{x}$ and $\mathrm{y}$, so in almost every single case, the value of y consists of two terms [11]:

$$
\mathrm{y}=\mathrm{yx}+\varepsilon
$$

where, $y$ is the actual value of the result attribute;

$\mathrm{yx}$ - the theoretical value of the result attribute found from the regression equation;

$\varepsilon$ is a random variable that characterizes the deviations of the actual value of the result attribute from the theoretical value found by the regression equation.

The data selection. As mentioned earlier, pair regression is a regression between two variables $-\mathrm{y}$ and $\mathrm{x}$. Here we will determine which indicators are most affected by changes in the company's revenue.

Table 3. Factors affecting changes in the company's revenue.

\begin{tabular}{|c|r|r|r|r|r|}
\hline Year & $\begin{array}{c}\text { Revenue of KMG EP, } \\
\text { million tenge }\end{array}$ & $\begin{array}{c}\text { Brent average } \\
\text { price }\end{array}$ & EUR/USD & \multicolumn{1}{|c|}{$\begin{array}{c}\text { Inflation } \% \\
\text { KZ }\end{array}$} & USD/Tenge \\
\hline 2010 & 609242 & 79,11 & 1,33 & 7,80 & 147,35 \\
\hline 2011 & 721194 & 110,91 & 1,39 & 7,40 & 146,62 \\
\hline 2012 & 797170 & 112,25 & 1,29 & 6,00 & 149,11 \\
\hline 2013 & 816712 & 113,25 & 1,37 & 4,8 & 154,35 \\
\hline 2014 & 845770 & 60,70 & 1,20 & 7,4 & 182,87 \\
\hline 2015 & 529812 & 36,57 & 1,09 & 13,6 & 340,60 \\
\hline 2016 & 727154 & 52,62 & 1,05 & 8,5 & 333,69 \\
\hline 2017 & 956457 & 61,19 & 1,19 & 7,1 & 332,81 \\
\hline 2018 & 270426 & 64,17 & 1,19 & 1,8 & 332,05 \\
\hline
\end{tabular}

This table shows the data that directly and/or indirectly have an impact on the company's revenues. The impact of the data should be evaluated by calculating the correlation coefficient. A correlation is a statistical relationship between two or more random variables (or variables that can be considered as such with some acceptable degree of accuracy).

The correlation coefficient is calculated using the formula [14]:

$$
r=\frac{\sum_{i=1}^{n}\left(x_{n}-\bar{x}\right)\left(y_{n}-\bar{y}\right)}{n \sigma_{x} \sigma_{y}}
$$


where $\mathrm{n}$ is the number of observations, $\mathrm{x}$ is the input variable, $\mathrm{y}$ is the output variable. The correlation coefficient values are always in the range from -1 to 1 and are interpreted as follows:

- if the correlation coefficient is close to 1 , then there is a positive correlation between the variables. In other words, there is a high degree of connection between the input and output variables. In this case, if the values of the input variable $\mathrm{x}$ increase, then the output variable will also increase;

- if the correlation coefficient is close to -1 , this means that there is a negative correlation between the variables. In other words, the behavior of the output variable will be the opposite of that of the input variable. If the value of $\mathrm{x}$ increases, then $\mathrm{y}$ will decrease, and Vice versa;

- intermediate values close to 0 will indicate a weak correlation between the variables and, consequently, a low dependency. In other words, the behavior of the input variable $\mathrm{x}$ will not affect the behavior of $y$ at all (or almost completely).

Table 4. Correlation Coefficients between factors.

\begin{tabular}{|l|l|}
\hline The correlation coefficient of the Proceeds of KMG EP Brent & 0,97 \\
\hline The correlation coefficient of the Proceeds of KMG EP for the EUR/USD & 0,66 \\
\hline The correlation coefficient of the Proceeds of KMG EP with Inflation & 0,02 \\
\hline The correlation coefficient of the Proceeds of KMG EP on the USD/Tenge & 0,14 \\
\hline
\end{tabular}

Table 4 shows that only oil prices -0.97 and the Euro/Dollar exchange rate -0.66 have the greatest impact on revenue. After making the calculations, according to the above calculation of the pair regression, we get the following stress testing with the following variations in Brent oil prices:

(1) at the price of Brent oil \$ 115, the company's revenue is $779,905+\varepsilon$ million tenge;

(2) if the price of Brent oil is $\$ 80$, the company's revenue is $530,376+\varepsilon$ million tenge;

(3) if the price of Brent oil is $\$ 40$, the company's revenue is $245,200+\varepsilon$ million tenge;

(4) at the price of Brent oil \$130, the company's revenue is $886846+\varepsilon$ million tenge;

(5) at the price of Brent oil \$ 150 , the company's revenue is $1,029,434+\varepsilon$ million tenge.

The next stress testing with pair regression will be with variations of the Euro/Dollar exchange rate:

(1) at the exchange rate of Euro / Dollar $\$ 1.15$, the company's revenue is $271,499+\varepsilon$ million tenge;

(2) at the exchange rate of Euro / Dollar $\$ 1.30$, the company's revenue is $472,501+\varepsilon$ million tenge;

(3) at the exchange rate of Euro / Dollar $\$ 1.40$, the company's revenue is $606,501+\varepsilon$ million tenge;

(4) at the exchange rate of Euro / Dollar $\$ 1.50$, the company's revenue is $740,502+\varepsilon$ million tenge;

(5) at the exchange rate of Euro / Dollar $\$ 1.60$, the company's revenue is $874,503+\varepsilon$ million tenge.

As can be seen from the calculations, the company benefits from high commodity prices and a low Dollar exchange rate against the Euro. If everything is clear with the first, the essence of the second is that when the Euro is more expensive, European companies and residents have more free funds that they can spend on gasoline, thereby spurring the consumption of petroleum products in the European Union.

Strategy for hedging price risks of JSC "KAZMUNAIGAS RD". Hedging is a method of protecting against the effects of price changes, often used in conditions of price volatility. The concept of hedging is to take a contractual position opposite to the position associated 
with risk. Choosing the right tactics for hedging price fluctuations depends on the hedged position. For example, an oil producer can predict that prices will decrease, and he needs to fix the future selling price of the cargo at the current level. He can conclude futures and forward contracts equal to the value of the cargo he will deliver if he wants to insure himself against a possible fall in prices in the future. Giving preference to a specific contract, the hedger selects the one whose price most closely matches the price set by him in the sales contracts [15].

By nature the hedging operation is divided into 2 groups:

1) long hedging - the purchase of a futures, which is made as insurance against possible future growth in the value of the goods upon purchase;

2) short hedging - one of the types of hedging (insurance) that is most in demand among sellers of cash goods. This is one of the types of hedging (insurance) that is most in demand among sellers of cash goods [16].

Ideal hedging is an abstract concept, which implies that hedging in the futures market completely eliminates the risk associated with this spot transaction. A traditional ideal hedge consists of a balance sheet position for a specific financial instrument, to which an equal in size, but opposite in direction, position in the futures market is selected. At the same time, the futures contracts are based on the same instrument that is accounted for by the balance sheet position. In practice, such compliance is not easy to achieve, but the content of a perfect hedge helps to understand the mechanism of action of futures contracts that aim to protect against interest rate risk.

Basic risk is the change in the difference between the price of a physical commodity and the price of futures for that commodity [17].

The results of the impact of potential changes in the basis on hedgers holding both short and long positions are presented in Table 5.

Table 5. Results of the impact of changes in the basis on hedgers.

\begin{tabular}{|l|l|l|l|l|}
\hline & \multicolumn{2}{|c|}{ Price increase } & \multicolumn{2}{c|}{ Price reduction } \\
\hline $\begin{array}{l}\text { Position on spot } \\
\text { and" paper " } \\
\text { transactions }\end{array}$ & $\begin{array}{l}\text { Spot prices are } \\
\text { rising more } \\
\text { slowly than } \\
\text { futures prices }\end{array}$ & $\begin{array}{l}\text { Spot prices are } \\
\text { rising faster } \\
\text { than futures } \\
\text { prices }\end{array}$ & $\begin{array}{l}\text { Spot prices fall } \\
\text { more slowly } \\
\text { than futures } \\
\text { prices }\end{array}$ & $\begin{array}{l}\text { Spot prices fall } \\
\text { faster than } \\
\text { futures prices }\end{array}$ \\
\hline $\begin{array}{l}\text { Bought spot } \\
\text { contracts-sold } \\
\text { futures } \\
\text { contracts }\end{array}$ & Loss & Profit & Loss \\
\hline $\begin{array}{l}\text { Sold spot } \\
\text { contracts- } \\
\text { bought futures } \\
\text { contracts }\end{array}$ & Profit & Loss & Loss & Profit \\
\hline \multicolumn{2}{|l|}{ Note: Compiled by the author based on materials [18] } & \\
\hline
\end{tabular}

Thus, in the "contango" market, seller hedgers ("short" hedgers) constantly make a profit when the basis narrows over time, and buyer hedgers ("long" hedgers) always lose. For companies that have stocks of goods, there is a real incentive to hedge using futures markets. The result will be compensation for all or part of the storage costs at the expense of the futures market. At the same time, in the backwardation market, "short" hedgers will constantly incur losses if cash and futures prices converge, and "long" hedgers will make a profit.

\section{Conclusion}


As a result of the analysis of price risk insurance strategies, we will summarize the results. Hedging is an important aspect of oil trading, as in the context of oil price volatility, it is important for large companies to protect themselves from risks and losses and make high profits [19]. However, it is impossible to fully protect yourself from price risk. Therefore, hedging allows you to protect yourself from unwanted financial losses, provides greater stability and flexibility in planning activities.

In most cases, Kazakh companies are not familiar with the practice of hedging, they have a wrong idea about it, which is why the concepts of hedging and speculation are mixed and they are afraid to "lose" on hedging.

Companies that export oil and oil products should use the hedging method to insure against unwanted changes in commodity prices, changes in trading volumes, profits, and losses. Proper application of this method will: improve the quality of risk management, reduce price fluctuations, stabilize profits.

In addition, today there is an understanding by companies that the purpose of hedging is not to make a profit, but to reduce financial risks and minimize possible losses, as well as the fact that hedging involves complete legal and financial purity of transactions. This is why companies use professional consultants, conduct seminars, and create their own hedging divisions, which include specialists in risk management, Finance, accounting, and law.

\section{REFERENCES:}

1. K. Mukhtarova, S. Ziyadin, S. Kupeshova, \& R. Doszhan, Economic annals-XXI, 168, 38-43 (2017). DOI: 10.21003/ea.V168-08

2. A. Zhanbolatova, S. Ziyadin, K. Zhumanov, A. Jumabekova, Banks and Bank Systems, 13 (1), 98-114 (2018). DOI: 10.21511/bbs.13(1).2018.10

3. G. Jaksybekova, A. Nurgaliyeva, A. Nurmagambetova, N. Gumar, A. Asanova, Espacios, 39 (16), 41 (2018)

4. R. Pukala, N. Vnukova, S. Achkasova, V. Smoliak, Economic Annals-XXI, 5 (6), 152156 (2017)

5. Official website of JSC “KAZMUNAIGAS” http://www.kmg.kz/eng/

6. U. Baymuratov, Money and Finance: a nonlinear system, 1

7. A. D. Chelekbay, Risk management in monetary and innovative activities: theory, world experience and practice of Kazakhstan, textbook (Almaty, 2007)

8. U. M. Iskakov, D. T. Bokhaev, E. A. Ruzieva, Financial markets and intermediaries: textbook (Ekonomika, Almaty, 2012)

9. R. Z. Ablukova, Financial management questions and answers: Textbook. Stipend, 256 (TC WELBY, Prospect Publishing House, 2004)

10. G. T. Abdrakhmanova, Hedging: concept, strategy and practice (LEM, Yeah., 2003)

11. Yu. N. Bobylev, D. N. Chetverikov, Factors of oil market development (IEPP, Yeah., 2006)

12. Yu. N. Bobylev, Factors of oil prices (IEPP, Yeah., 2006)

13. InfoTech Terminal, Information services for the oil and gas business http://www.itek.ru/

14. RiskManage, Hedging and risk management methods, risk management, articles on risk analysis http://www.riskmanage.ru/

15. Oil, Gas and the Stock Market http://www.ngfr.ru/

16. World Factbook, CIA https://www.cia.gov/

17. The energy information administration of the United States http://www.eia.doe.gov/

18. Annual report of JSC "EP KazMunaiGas" for the year (2016)

19. S. Ziyadin, K. Malayev, G. Yessenova, \& A. Beyzhanova, E3S Web of Conferences, 135, 04025 (2019). DOI: 10.1051/e3sconf/201913504025 